\title{
Double Decline Balance Method pada Aktiva Tetap Berwujud
}

\author{
Dina Satriani $^{1}$, Vina Vijaya Kusuma ${ }^{2}$, Sefti Melinda ${ }^{3}$ \\ ${ }^{1}$ Program Studi Komputerisasi Akuntansi STTIKOM Insan Unggul Cilegon, ${ }^{2}$ Program Studi \\ Sistem Informasi STTIKOM Insan Unggul Cilegon, ${ }^{3}$ Program Studi Sistem Informasi \\ Universitas Raharja \\ Email : "1aylaku@yahoo.com, vinavijaya@gmail.com, sefti@ raharja.info
}

Primkokas memiliki aset yang digunakan untuk kegiatan operasional sehari-hari. Aset tersebut memiliki umur ekonomis lebih dari satu tahun serta tidak untuk dijual kembali. Perusahaan biasanya mengelola aset menjadi sebuah investasi jangka panjang yang disebut aktiva tetap. Aktiva tetap memerlukan suatu pengelolaan dan kebijakan khusus dalam menghitung penyusutan dengan menggunakan metode penyusutan saldo menurun ganda (double decline balance method). Hasil dari penelitian ini adalah dalam menghitung penyusutan menggunakan metode saldo menurun ganda dilakukan dengan cara mengalikan tarif penyusutan dua kali tarif penyusutan yang dipercepat dari nilai buku awal setiap tahunnya, yakni jumlah biaya perolehan dikurangi akumulasi penyusutan.

Kata Kunci: Penyusutan Aktiva tetap, Saldo Menurun Ganda (Double Decline Balance Mathod), Metode Penyustan.

\begin{abstract}
Primkokas has assets used for daily operational activities. The asset has an economic lifespan of more than one year and is not for resale. In this case, the company will manage the asset into a long-term investment called fixed assets. Fixed assets require a management and special policy in calculating depreciation by using the double declining method. The result of this study is in calculating depreciation using the double declining balance method is done by multiplying the depreciation rate twice the accelerated depreciation rate from the initial book value each year. the amount of acquisition costs minus accumulated depreciation.
\end{abstract}

Keywords: depreciation of fixed assets, double declining balance method, depreciation method

\section{PENDAHULUAN}

Aktiva tetap yang memiliki umur ekonomis akan mengalami penurunan yang disebabkan pemakaian, kerusakan dan ketinggalan zaman karena faktor ekonomis dan faktor teknis, maka aktiva ini memerlukan suatu pengelolaan dan kebijakan khusus, baik dalam penggunaan, pemeliharaan dan pencatatan akuntansinya yang akan mempengaruhi laba pada perusahaan di laporan keuangan.

Metode saldo menurun ganda adalah metode penyusutan aktiva tetap yang ditentukan berdasarkan persentase tertentu dan dihitung dari harga buku pada tahun yang bersangkutan. Kelebihan dari metode ini adalah lebih hemat dari segi biaya bila dibandingkan dengan metode penyusutan garis lurus, namun kekurangnya adalah lebih rumit dan sulit diaplikasikan dalam akuntansi karena banyaknya variable perhitungan yang harus dilibatkan. Maka dari itu banyak perusahaan menghindari menggunakan metode ini dalam perhitungan aktiva tetapnya. 
Primer Koperasi Karyawan Krakatau Steel atau Primkokas merupakan perusahaan yang bergerak di bidang koperasi di Kota Cilegon, dimana Primkokas bertujuan untuk memenuhi kebutuhan-kebutuhan, khususnya kepada karyawan PT. Krakatau Steel. Untuk mendukung kegiatan operasional, Primkokas tentunya memiliki aset atau aktiva tetap. Aktiva tetap pada Primkokas terdiri dari aktiva berwujud, seperti berikut : Peralatan, Perlengkapan, Kendaraan, Mesin, dan Bangunan. Primkokas sendiri telah melakukan perhitungan penyusutan aktiva tetap menggunakan metode garis lurus, sama halnya dengan perusahaan lain dengan alasan metode tersebut sangat sederhana perhitungannya. Ada beberapa cara untuk mengetahui analisa penyusutan aktiva tetap, dalam hal ini penulis menggunakan metode saldo menurun ganda, untuk mengetahui hasil perhitungan penyusutan aktiva yang lebih baik digunakan perusahaan dalam memperoleh keuntungan dan laporan keuangan yang baik.

\section{Rumusan Masalah}

Dalam penelitian ini, rumusan masalah yang akan diangkat adalah terkait dengan:

1. Bagaimana analisa penyusutan aktiva tetap menggunakan metode saldo menurun ganda?

\section{LANDASAN TEORI DAN LITERATURE REVIEW}

\section{Landasan Teori}

\section{Pengertian Aktiva Tetap}

Aset tetap (fixed assets) adalah aset yang secara fisik dapat dilihat keberadaannya dan sifatnya relatif permanen serta memiliki masa kegunaan (useful life) yang panjang. Hery (2021:61)

Aktiva tetap merupakan adalah yang dibeli dengan tujuan untuk dipergunakan secara aktif didalam operasional perusahaan dalam rangka mencari laba, dan memberikan masa manfaat satu periode akuntansi, Kadek (2021:71)

\section{Jenis Aktiva Tetap}

Aktiva tetap dibedakan menjadi dua yaitu aktiva tetap berwujud dan aktiva tetap tidak berwujud.

a. Aktiva tetap ini contohnya; kendaraan, mesin, dan peralatan

b. Aktiva tetap tidak berwujud meliputi ; goodwill dan hak paten

\section{Double Decline Balance Method}

Menurut Erwin (2020:99) metode saldo menurun (double declining method) adalah metode penyusutan yang dipercepat, yaitu dengan cara mengalikan tarif penyusutan yang dipercepat dari nilai buku awal setiap tahunnya yaitu jumlah biaya perolehan dikurangi akumulasi penyusutan.

Menurut Hery (2021:117) metode saldo menurun ganda adalah dimana beban penyusutan periodik dihitung dengan cara mengalikan suatu tarif persentase (konstan) ke nilai buku aset yang kian menurun. Besarnya tarif penyusutan yang umum dipakai adalah dua kali tarif penyusutan garis lurus. Dengan metode saldo menurun ganda, besarnya estimasi nilai residu tidak digunakan dalam perhitungan, dan penyusutan tidak akan dilanjutkan apabila nilai buku aset telah sama atau mendekati estimasi nilai residunya.

Menurut (2020:67) metode saldo menurun ganda (double declining method) menghitung tarif penyusutan garis lurus tanpa nilai residu, lalu dikalikan dua. Metode saldo menurun ganda ini memperhitungkan nilai buku aset setiap awal periode.(harga perolehan / umur ekonomis) x 2 = penyusutan 
Dari beberapa referensi diatas dapat disimpulkan metode saldo menurun berganda, beban depresiasi mengalami perubahan setiap tahunnya, awal masa manfaat beban depresiasi cenderung lebih besar, kemudian akan semakin kecil setiap tahunnya sampai akhir masa manfaat suatu aset tetap. Hal tersebut didasarkan suatu pemikiran bahwa aset tetap akan lebih besar beban penggunaannya pada awal masa manfaatnya dan cenderung semakin kecil beban penggunaannya serinng bertambahnya umur penggunaan aset tetap.

\section{Literature Review}

Menurut skripsi (Jayanti 2018), dari Universitas Mercu Buana yang berjudul “Analisis Penerapan Metode Penyusutan Aktiva Tetap Dan Implikasinya Terhadap Laba Perusahaan (Studi Kasus Pada PT. Dago Endah)". Penelitian ini membahas penyusutan aktiva tetap menggunakan tiga metode, yakni metode garis lurus, metode saldo menurun ganda dan metode jumlah angka tahun. Hasilnya untuk aktiva lapangan golf perusahaan, sarana umum, dan mesin tetap menggunakan metode persentase tetap dari nilai buku atau metode yang sudah digunakan selama ini oleh perusahaan. Tetapi untuk aktiva bangunan menggunakan metode jumlah angka tahun dan untuk lapangan golf PGB, kendaraan, alatberat, mebeul, perlengkapan restoran, peralatan kantor dan aktiva lainnya menggunakan metode saldo menurun ganda sehingga laba perusahaan menjadi besar.

Menurut jurnal (Wico J Tarigan 2019), dari Universitas Simalungun Pematangsiantar dengan judul "Analisis Penerapan Metode Penyusutan Aktiva Tetap dan Pengaruhnya Terhadap Laba Perusahaan Pada PT. Jhonson \& Jhonson”. Dalam jurnal ini membahas evaluasi kebijakan metode penyusutan aktiva tetap danpengaruhnya terhadap laba perusahaan. Dalam hal ini penulis menggunakan 3 metode dalam membuat perbandingan dalam penyusutan dan pengaruhnya terhadap laba perusahaan. Terdapat pengaruh yang signifikan antara penerapan metode penyusutan yang diterapkan oleh perusahaan (metode garis lurus ) dengan metode yang diajukan oleh penulis ( metode jumlah angka tahun dan metode saldo menurun ganda ) terhadap laba usaha perusahaan.

Menurut jurnal (Lestari 2018), dari UIN Sunan Gunung Djati Bandung dengan judul "Perhitungan Penyusutan Aset Tetap Menggunakan Metode Saldo Menurun Ganda (Double Decline Method) Di Dinas Perhubungan Kabupaten Bandung". Jurnal ini membahas tentang permasalahan terkait perolehan aset tetap yang mana keberadaan dan kondisi aset tetap yang masih diragukan karena banyak aset tetap yang tidak diupdate, penerapan metode penyusutan aset tetap yang dirasa belum sesuai untuk jenis aset tetap yang memiliki masa manfaat di bawah 10 tahun. Metode penelitian yang digunakan dalam penelitian ini adalah metode verifikatif dengan desain penelitian kualitatif. Pengumpulan data dilakukan melalui observasi. Hasil dari pembahasan penelitian ini adalah metode penyusutan garis lurus lebih cocok digunakan untuk aset yang memiliki masa manfaat di atas 10 tahun dan metode saldo menurun ganda lebih cocok digunakan untuk aset yang memiliki masa manfaat di bawah 10 tahun.

\section{PEMECAHAN MASALAH}

\section{Objek Penelitian}

Objek penelitian adalah apa yang akan diselidiki selama kegiatan penelitian. Beberapa persoalan sekiranya perlu dipahami agar bisa menentukan dan menyusun objek penelitian dalam metode penelitian ini dengan baik.

Dalam penelitian ini dilakukan riset pada Primkokas Krakatau Steel dengan beralamat, jalan KH Yasin Beji Gedung Krakatau Junction $3{ }^{\text {rd }}$ Floor.

\section{Jenis Penelitian}

Jenis penelitian yang dilakukan adalah penelitian deskriptif. Penelitian ini dilakukan dengan cara observasi dan wawancara. Observasi dilakukan pada tempat penelitian, yakni Primkokas. Sumber Primer dan Intern dari jajaran dan staff Primkokas. Penulis menggunakan 
data aktiva tetap untuk menganalisa penyusutan menggunakan metode saldo menurun ganda, yang bertujuan untuk mengetahui perbandingan penyusutan aktiva tetap menggunakan metode yang telah dipakai Primkokas yakni metode garis lurus. Berdasarkan data yang diperoleh dari Primkokas, penulis tidak dapat memanipulasi data-data terkait dengan analisis penyusutan aktiva tetap.

\section{Metode Pengumpulan Data}

Agar bisa menghasilkan penelitian yang teliti dan hasil memuaskan, beberapa metode pengumpulan data pada penelitian ini, diantara lain:

1) Metode Obsevarsi (Pengamatan langsung)

Obsevarsi merupakan teknik pengumpulan data yang sering digunakan dalam penelitian kualitatif. Observasi bentuk dari kegiatan dengan menggunakan panca indera, penglihatan, pendengaran, penciuman untuk memperoleh informasi yang perlu untuk menjawab masalah penelitian. Hasil observasi berupa aktivitas, kejadian, peristiwa, objek, kondisi atau suasana tertentu, dan perasaan emosi seseorang.

2) Metode Wawancara

Wawancara merupakan metode utama di dalam penelitian studi kasus kualitatif pada khususnya dan pedekatan penelitian kualitatif pada umumnya. Bentuk-bentuk wawancara dapat wawancara individu dan kelompok.

Dengan wawancara, informasi yang bisa didapatkan dengan cara bertanya secara langsung kepada sumber wawancara. Melakukan wawancara butuh persiapan panduan wawancara, yang dikembangkan dari hasil kajian literatul.

3) Metode Buku Referensi

Buku Referensi adalah buku yang memuat informasi ringkas dan padat semacam ensiklopedia, kamus, atlas, dan jenis-jenis buku pedoman lainnya.Buku yang memuat informasi yang bersifat mudah untuk ditemukan agar pencarian data menjadi lebih efesien.Kualitas dari buku referensi tidak ditentukan bagaimana penulisan buku tersebut dilakukan, tetapi lebih dari jumlah data dan referensi data secara kompreteheren.

\section{Operasional Variabel}

1. Metode Saldo Menurun Ganda

Penyusutan $=\frac{1}{\text { Masa manfaat }} \times 2 \times 100 \%$

\section{Identifikasi Variabel}

Dalam identifikasi variabel terdapat dua variabel yaitu : Variabel $X$ : Analisis penyusutan aktiva tetap Variabel Y : Perlakuan terhadap aktiva tetap

\section{Pembahasan Penelitian}

\section{Pelaksanaan Penyusutan Aktiva Tetap Pada Primkokas}

Pelaksanaan penyusutan aktiva tetap pada Primkokas dilakukan dengan metode garis lurus sesuai standarisasi yang berlaku pada perusahaan. Dan disajikan dalam bentuk laporan daftar aktiva tetap yang masih berfungsi yaitu peralatan administrasi \& umum, kendaraan, bangunan, dan mesin. Dimana dalam perhitungan beban penyusutan aktiva tetap didasarkan atas masa manfaat dari setiap jenis aktiva yang bersangkutan, yang dihitung secara tahunan. Penyusutan aktiva tetap dihitung setelah ahun perolehan aktiva tetap dan pembebanannya dilakukan tiap akhir periode pembukuan.

Sama seperti perusahaan lain pada umumnya, Primkokas dalam menghitung penyusutan aktiva tetapnya menggunakan metode garis lurus karna metode ini adalah metode yang paling mudah perhitungannya, yakni nilai pembebanan penyusutan tiap tahunnya sama. Dan selama ini 
bagian keuangan tidak ada masalah dalam melakukan perhitungan penyusutan aktiva tetap menggunakan metode tersebut.

Bagian keuangan melakukan perhitungan penyusutan aktiva tetap menggunakan metode garis lurus tanpa nilai residu atau nilai taksiran pada akhir periode masa manfaat aktiva tetapnya. Hal ini dilakukan karna menurut kebijakan perusahaan aktiva tetap tidak memiliki nilai lagi setelah habis periode penyusutan.

\section{Analisis Aktiva Tetap Menggunakan Metode Saldo Menurun Ganda}

Penulis melakukan analisis perhitungan penyusutan aktiva tetap (peralatan) menggunakan metode saldo menurun ganda. Dalam menghitung penyusutan peralatan Primkokas, memiliki beberapa unsur yang akan digunakan seperti ; tarif penyusutan, masa manfaat, harga perolehan, beban penyusutan, akumulasi penyusutan, dan nilai buku akhir tahun.

Peralatam yang dimiliki Primkokas termasuk dalam aktiva tetap kolom tarif penyusutan sebesar $40 \%$ untuk masa manfaat 5 tahun dan $67 \%$ untuk masa manfaat 3 tahun, karena perhitungannya diperoleh dari hasil :
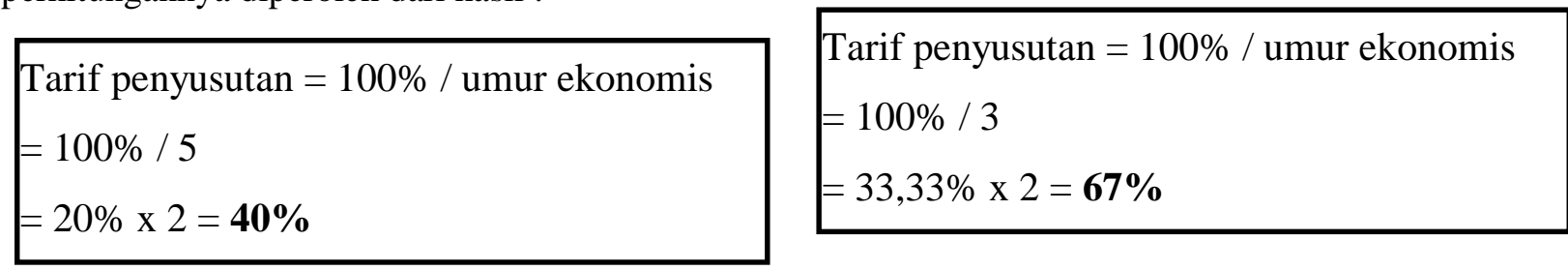

Tabel Penyusutan Menggunakan Metode Saldo Menurun Ganda

\begin{tabular}{|c|c|r|r|r|}
\hline \multicolumn{2}{|c|}{ Tahun } & Beban Penyusutan & Akumulasi Penyusutan & Nilail Buku \\
\hline 1 & 2014 & Rp 1.200.000 & Rp 1.200.000 & Rp 600.000 \\
\hline 2 & 2015 & Rp 402.000 & Rp 1.602.000 & Rp 198.000 \\
\hline 3 & 2016 & Rp 132.660 & Rp 1.734.660 & Rp 65.340 \\
\hline
\end{tabular}


Penyusutan Aktiva Tetap Menggunakan Metode Saldo Menurun Ganda

\begin{tabular}{|c|c|c|c|c|c|c|c|c|c|}
\hline No & Nama Aktiva & $\begin{array}{c}\text { Tanggal } \\
\text { Perolehan }\end{array}$ & $\begin{array}{c}\text { Masa } \\
\text { Manfaat }\end{array}$ & \begin{tabular}{|} 
Harga \\
Perolehan
\end{tabular} & Tarif & Thn & $\begin{array}{c}\text { Beban } \\
\text { Penyusutan }\end{array}$ & $\begin{array}{l}\text { Akumulasi } \\
\text { Penyusutan }\end{array}$ & $\begin{array}{c}\text { Niai } \\
\text { Buku }\end{array}$ \\
\hline 1 & $\begin{array}{c}\text { Fujitsu LifeBook } \\
\text { LH532V-V4- } \\
3210\end{array}$ & $05 / 02 / 2013$ & 5 & 6.499 .000 & $\begin{array}{l}40 \% \\
40 \% \\
40 \% \\
40 \% \\
40 \%\end{array}$ & $\begin{array}{l}2014 \\
2015 \\
2016 \\
2017 \\
2018\end{array}$ & $\begin{array}{c}2.599 .600 \\
1.559 .760 \\
935.856 \\
561.514 \\
336.908\end{array}$ & $\begin{array}{l}2.599 .600 \\
4.159 .360 \\
5.095 .216 \\
5.656 .730 \\
5.993 .638\end{array}$ & $\begin{array}{l}3.899 .400 \\
2.339 .640 \\
1.403 .784 \\
842.270 \\
505.362\end{array}$ \\
\hline 2 & $\begin{array}{l}\text { Kursi Putar } \\
\text { Direktur }\end{array}$ & $20 / 03 / 2013$ & 3 & 1.800 .000 & $\begin{array}{l}67 \% \\
67 \% \\
67 \%\end{array}$ & $\begin{array}{l}2014 \\
2015 \\
2016\end{array}$ & $\begin{array}{c}1.200 .000 \\
402.000 \\
132.660\end{array}$ & $\begin{array}{l}1.200 .000 \\
1.602 .000 \\
1.734 .660\end{array}$ & $\begin{array}{c}600.000 \\
198.000 \\
65.340\end{array}$ \\
\hline 3 & $\begin{array}{l}\text { Handy Talkie } \\
\text { Type FC } 08\end{array}$ & $16 / 10 / 2013$ & 3 & 750.000 & $\begin{array}{l}67 \% \\
67 \% \\
67 \%\end{array}$ & $\begin{array}{l}2014 \\
2015 \\
2016\end{array}$ & $\begin{array}{c}500.000 \\
167.500 \\
55.275\end{array}$ & $\begin{array}{l}500.000 \\
667.500 \\
722.775\end{array}$ & $\begin{array}{l}250.000 \\
82.500 \\
27.225\end{array}$ \\
\hline 4 & $\begin{array}{c}\text { Handy Talkie } \\
\text { Type FC } 08\end{array}$ & $16 / 10 / 2013$ & 3 & 750.000 & $\begin{array}{l}67 \% \\
67 \% \\
67 \%\end{array}$ & $\begin{array}{l}2014 \\
2015 \\
2016\end{array}$ & $\begin{array}{c}500.000 \\
167.500 \\
55.275\end{array}$ & $\begin{array}{l}500.000 \\
667.500 \\
722.775\end{array}$ & $\begin{array}{l}250.000 \\
82.500 \\
27.225\end{array}$ \\
\hline 5 & $\begin{array}{l}\text { Handy Talkie } \\
\text { Type FC } 08\end{array}$ & $16 / 10 / 2013$ & 3 & 750.000 & $\begin{array}{l}67 \% \\
67 \% \\
67 \%\end{array}$ & $\mid \begin{array}{l}2014 \\
2015 \\
2016\end{array}$ & $\begin{array}{c}500.000 \\
167.500 \\
55.275\end{array}$ & $\begin{array}{r}500.000 \\
667.500 \\
722.775\end{array}$ & $\begin{array}{l}250.000 \\
82.500 \\
27.225\end{array}$ \\
\hline 6 & $\begin{array}{l}\text { Handy Talkie } \\
\text { Type FC } 08\end{array}$ & $16 / 10 / 2013$ & 3 & 750.000 & $\begin{array}{l}67 \% \\
67 \% \\
67 \%\end{array}$ & $\mid \begin{array}{l}2014 \\
2015 \\
2016\end{array}$ & $\begin{array}{c}500.000 \\
167.500 \\
55.275\end{array}$ & $\begin{array}{l}500.000 \\
667.500 \\
722.775\end{array}$ & $\begin{array}{l}250.000 \\
82.500 \\
27.225\end{array}$ \\
\hline 7 & $\begin{array}{l}\text { Handy Talkie } \\
\text { Type FC } 08\end{array}$ & $16 / 10 / 2013$ & 3 & 750.000 & $67 \%$ & 2014 & 500.000 & 500.000 & 250.000 \\
\hline
\end{tabular}




\begin{tabular}{|c|c|c|c|c|c|c|c|c|c|}
\hline & & & & & $\begin{array}{l}67 \% \\
67 \%\end{array}$ & $\begin{array}{l}2015 \\
2016\end{array}$ & $\begin{array}{l}167.500 \\
55.275\end{array}$ & $\begin{array}{l}667.500 \\
722.775\end{array}$ & $\begin{array}{l}82.500 \\
27.225\end{array}$ \\
\hline 8 & $\begin{array}{l}\text { Camera CCTV } \\
\text { Avtec AVN } 457\end{array}$ & $23 / 10 / 2013$ & 3 & 2.960 .000 & $\begin{array}{l}67 \% \\
67 \% \\
67 \%\end{array}$ & $\begin{array}{l}2014 \\
2015 \\
2016\end{array}$ & $\begin{array}{c}1.973 .333 \\
661.067 \\
218.152\end{array}$ & $\begin{array}{l}1.973 .333 \\
2.634 .400 \\
2.852 .552\end{array}$ & $\begin{array}{l}986.667 \\
325.600 \\
107.448\end{array}$ \\
\hline 9 & $\begin{array}{l}\text { Camera CCTV } \\
\text { Avtec AVN } 457\end{array}$ & $23 / 10 / 2013$ & 3 & 2.960 .000 & $\begin{array}{l}67 \% \\
67 \% \\
67 \%\end{array}$ & $\begin{array}{l}2014 \\
2015 \\
2016\end{array}$ & $\begin{array}{c}1.973 .333 \\
661.067 \\
218.152\end{array}$ & $\begin{array}{l}1.973 .333 \\
2.634 .400 \\
2.852 .552\end{array}$ & $\begin{array}{l}986.667 \\
325.600 \\
107.448\end{array}$ \\
\hline 10 & $\begin{array}{l}\text { Camera CCTV } \\
\text { Avtec AVN } 457\end{array}$ & $23 / 10 / 2013$ & 3 & 2.960 .000 & $\begin{array}{l}67 \% \\
67 \% \\
67 \%\end{array}$ & $\begin{array}{l}2014 \\
2015 \\
2016\end{array}$ & $\begin{array}{c}1.973 .333 \\
661.067 \\
218.152\end{array}$ & $\begin{array}{l}1.973 .333 \\
2.634 .400 \\
2.852 .552\end{array}$ & $\begin{array}{l}986.667 \\
325.600 \\
107.448\end{array}$ \\
\hline 11 & $\begin{array}{l}\text { Camera CCTV } \\
\text { Avtec AVN } 457\end{array}$ & $23 / 10 / 2013$ & 3 & 2.960 .000 & $\begin{array}{l}67 \% \\
67 \% \\
67 \%\end{array}$ & $\begin{array}{l}2014 \\
2015 \\
2016\end{array}$ & $\begin{array}{c}1.973 .333 \\
661.067 \\
218.152\end{array}$ & $\begin{array}{l}1.973 .333 \\
2.634 .400 \\
2.852 .552\end{array}$ & $\begin{array}{l}986.667 \\
325.600 \\
107.448\end{array}$ \\
\hline 12 & $\begin{array}{l}\text { Camera CCTV } \\
\text { Avtec AVN } 457\end{array}$ & $23 / 10 / 2013$ & 3 & 2.960 .000 & $\begin{array}{l}67 \% \\
67 \% \\
67 \%\end{array}$ & $\begin{array}{l}2014 \\
2015 \\
2016\end{array}$ & $\begin{array}{c}1.973 .333 \\
661.067 \\
218.152\end{array}$ & $\begin{array}{l}1.973 .333 \\
2.634 .400 \\
2.852 .552\end{array}$ & $\begin{array}{l}986.667 \\
325.600 \\
107.448\end{array}$ \\
\hline 13 & $\begin{array}{c}\text { Camera CCTV } \\
\text { Avtec AVN } 457\end{array}$ & $23 / 10 / 2013$ & 3 & 2.960 .000 & $\begin{array}{l}67 \% \\
67 \% \\
67 \%\end{array}$ & $\begin{array}{l}2014 \\
2015 \\
2016\end{array}$ & $\begin{array}{c}1.973 .333 \\
661.067 \\
218.152\end{array}$ & $\begin{array}{l}1.973 .333 \\
2.634 .400 \\
2.852 .552\end{array}$ & $\begin{array}{l}986.667 \\
325.600 \\
107.448\end{array}$ \\
\hline 14 & $\begin{array}{l}\text { Camera CCTV } \\
\text { Avtec AVN } 457\end{array}$ & $23 / 10 / 2013$ & 3 & 2.960 .000 & $\begin{array}{l}67 \% \\
67 \% \\
67 \%\end{array}$ & $\begin{array}{l}2013 \\
2014 \\
2015\end{array}$ & $\begin{array}{c}1.973 .333 \\
661.067 \\
218.152\end{array}$ & $\begin{array}{l}1.973 .333 \\
2.634 .400 \\
2.852 .552\end{array}$ & $\begin{array}{l}986.667 \\
325.600 \\
107.448\end{array}$ \\
\hline 15 & $\begin{array}{l}\text { Camera CCTV } \\
\text { Avtec AVN } 457\end{array}$ & $23 / 10 / 2013$ & 3 & 2.960 .000 & $67 \%$ & 2014 & 1.973 .333 & 1.973 .333 & 986.667 \\
\hline
\end{tabular}




\begin{tabular}{|c|c|c|c|c|c|c|c|c|c|}
\hline & & & & & $\begin{array}{l}67 \% \\
67 \%\end{array}$ & $\begin{array}{l}2015 \\
2016\end{array}$ & $\begin{array}{l}661.067 \\
218.152\end{array}$ & $\begin{array}{l}2.634 .400 \\
2.852 .552\end{array}$ & $\begin{array}{l}325.600 \\
107.448\end{array}$ \\
\hline 16 & TV LCD 32" & $24 / 10 / 2013$ & 3 & 3.000 .000 & $\begin{array}{l}67 \% \\
67 \% \\
67 \%\end{array}$ & $\begin{array}{l}2014 \\
2015 \\
2016\end{array}$ & $\begin{array}{c}2.000 .000 \\
670.000 \\
221.100\end{array}$ & $\begin{array}{l}2.000 .000 \\
2.670 .000 \\
2.891 .100\end{array}$ & $\begin{array}{r}1.000 .000 \\
330.000 \\
108.900\end{array}$ \\
\hline 17 & $\begin{array}{l}\text { Radio Nano } \\
\text { Station M5 }\end{array}$ & 19/01/2013 & 3 & 10.640 .000 & $\begin{array}{l}67 \% \\
67 \% \\
67 \%\end{array}$ & $\begin{array}{l}2014 \\
2015 \\
2016\end{array}$ & $\begin{array}{c}7.093 .333 \\
2.376 .267 \\
784.168\end{array}$ & $\begin{array}{c}7.093 .333 \\
9.469 .600 \\
10.253 .768\end{array}$ & $\begin{array}{c}3.546 .667 \\
1.170 .400 \\
386.232\end{array}$ \\
\hline 18 & $\begin{array}{l}\text { Printer POS } \\
\text { Bixolon }\end{array}$ & $25 / 04 / 2013$ & 3 & 2.515 .000 & $\begin{array}{l}67 \% \\
67 \% \\
67 \%\end{array}$ & $\begin{array}{l}2014 \\
2015 \\
2016\end{array}$ & $\begin{array}{c}1.676 .667 \\
561.683 \\
185.356\end{array}$ & $\begin{array}{l}1.676 .667 \\
2.238 .350 \\
2.423 .706\end{array}$ & $\begin{array}{c}838.333 \\
276.650 \\
91.295\end{array}$ \\
\hline 19 & $\begin{array}{c}\text { Cisco WS- } \\
\text { C2960-24LT-L }\end{array}$ & $22 / 10 / 2013$ & 3 & 16.445 .000 & $\begin{array}{l}67 \% \\
67 \% \\
67 \%\end{array}$ & $\mid \begin{array}{l}2014 \\
2015 \\
2016\end{array}$ & $\begin{array}{c}10.963 .333 \\
3.672 .717 \\
1.211 .997\end{array}$ & $\begin{array}{r}10.963 .333 \\
14.636 .050 \\
15.848 .047\end{array}$ & $\begin{array}{c}5.481 .667 \\
1.808 .950 \\
596.954\end{array}$ \\
\hline 20 & $\begin{array}{l}\text { Kitchen } \\
\text { Equipment }\end{array}$ & $31 / 01 / 2014$ & 3 & 46.265 .000 & $\begin{array}{l}67 \% \\
67 \% \\
67 \%\end{array}$ & $\mid \begin{array}{l}2015 \\
2016 \\
2017\end{array}$ & $\begin{array}{c}30.843 .333 \\
10.332 .517 \\
3.409 .731\end{array}$ & $\begin{array}{l}30.843 .333 \\
41.175 .850 \\
44.585 .581\end{array}$ & $\begin{array}{c}15.421 .66 \\
7 \\
5.089 .150 \\
1.679 .420\end{array}$ \\
\hline 21 & Grinder Carimali & $31 / 01 / 2014$ & 3 & 8.500 .000 & $\begin{array}{l}67 \% \\
67 \% \\
67 \%\end{array}$ & $\begin{array}{l}2015 \\
2016 \\
2017\end{array}$ & $\begin{array}{c}5.666 .667 \\
1.898 .333 \\
626.450\end{array}$ & $\begin{array}{l}5.666 .667 \\
7.565 .000 \\
8.191 .450\end{array}$ & $\begin{array}{c}2.833 .333 \\
935.000 \\
308.550\end{array}$ \\
\hline 22 & Kursi Futura & 24/06/2014 & 3 & 19.500 .000 & $\begin{array}{l}67 \% \\
67 \% \\
67 \%\end{array}$ & $\mid \begin{array}{l}2015 \\
2016 \\
2017\end{array}$ & $\begin{array}{r}13.000 .000 \\
4.355 .000 \\
1.437 .150\end{array}$ & $\begin{array}{r}13.000 .000 \\
17.355 .000 \\
18.792 .150\end{array}$ & $\left|\begin{array}{c}6.500 .000 \\
2.145 .000 \\
707.850\end{array}\right|$ \\
\hline 23 & Meja Kursi Kayu & $18 / 06 / 2014$ & 3 & 3.240 .000 & $67 \%$ & 2015 & 2.160 .000 & 2.160 .000 & 1.080 .000 \\
\hline
\end{tabular}




\begin{tabular}{|c|c|c|c|c|c|c|c|c|c|}
\hline & & & & & $\begin{array}{l}67 \% \\
67 \%\end{array}$ & $\begin{array}{l}2016 \\
2017\end{array}$ & $\begin{array}{l}723.600 \\
238.788\end{array}$ & $\begin{array}{l}2.883 .600 \\
3.122 .388\end{array}$ & $\begin{array}{l}356.400 \\
117.612\end{array}$ \\
\hline 24 & Meja Kursi Ecco & 02/07/2014 & 3 & 4.860 .000 & $\begin{array}{l}67 \% \\
67 \% \\
67 \%\end{array}$ & $\begin{array}{l}2015 \\
2016 \\
2017\end{array}$ & $\begin{array}{c}3.240 .000 \\
1.085 .400 \\
358.182\end{array}$ & $\begin{array}{l}3.240 .000 \\
4.325 .400 \\
4.683 .582\end{array}$ & $\begin{array}{r}1.620 .000 \\
534.600 \\
176.418\end{array}$ \\
\hline 25 & Meja & 14/07/2014 & 3 & 3.900 .000 & $\begin{array}{l}67 \% \\
67 \% \\
67 \%\end{array}$ & $\begin{array}{l}2015 \\
2016 \\
2017\end{array}$ & $\begin{array}{c}2.600 .000 \\
871.000 \\
287.430\end{array}$ & $\begin{array}{l}2.600 .000 \\
3.471 .000 \\
3.758 .430\end{array}$ & $\begin{array}{r}1.300 .000 \\
429.000 \\
141.570\end{array}$ \\
\hline 26 & $\begin{array}{c}\text { Lemari Arsip } \\
\text { Kaca } 900 \text { Q }\end{array}$ & 02/10/2015 & 5 & 1.147 .500 & $\begin{array}{l}40 \% \\
40 \% \\
40 \% \\
40 \% \\
40 \%\end{array}$ & $\begin{array}{l}2016 \\
2017 \\
2018 \\
2019 \\
2020\end{array}$ & $\begin{array}{c}459.000 \\
275.400 \\
165.240 \\
99.144 \\
59.486\end{array}$ & $\begin{array}{c}459.000 \\
734.400 \\
899.640 \\
998.784 \\
1.058 .270\end{array}$ & $\begin{array}{c}688.500 \\
413.100 \\
247.860 \\
148.716 \\
89.230\end{array}$ \\
\hline 27 & $\begin{array}{l}\text { Lemari Arsip } \\
\text { Kaca } 900 \text { Q }\end{array}$ & 02/10/2015 & 5 & 1.147 .500 & $\begin{array}{l}40 \% \\
40 \% \\
40 \% \\
40 \% \\
40 \%\end{array}$ & $\begin{array}{l}2016 \\
2017 \\
2018 \\
2019 \\
2020\end{array}$ & $\begin{array}{c}459.000 \\
275.400 \\
165.240 \\
99.144 \\
59.486\end{array}$ & $\begin{array}{c}459.000 \\
734.400 \\
899.640 \\
998.784 \\
1.058 .270\end{array}$ & $\begin{array}{c}688.500 \\
413.100 \\
247.860 \\
148.716 \\
89.230\end{array}$ \\
\hline 28 & Kursi merk INTI & 15/07/2015 & 3 & 1.000 .000 & $\begin{array}{l}67 \% \\
67 \% \\
67 \%\end{array}$ & $\begin{array}{l}2016 \\
2017 \\
2018\end{array}$ & $\begin{array}{c}666.667 \\
223.333 \\
73.700\end{array}$ & $\begin{array}{l}666.667 \\
890.000 \\
963.700\end{array}$ & $\begin{array}{c}333.333 \\
110.000 \\
36.300\end{array}$ \\
\hline 29 & Kursi merk INTI & 15/07/2015 & 3 & 1.000 .000 & $\begin{array}{l}67 \% \\
67 \% \\
67 \%\end{array}$ & $\begin{array}{l}2016 \\
2017 \\
2018\end{array}$ & $\begin{array}{c}666.667 \\
223.333 \\
73.700\end{array}$ & $\begin{array}{l}666.667 \\
890.000 \\
963.700\end{array}$ & $\begin{array}{c}333.333 \\
110.000 \\
36.300\end{array}$ \\
\hline
\end{tabular}




\begin{tabular}{|c|c|c|c|c|c|c|c|c|c|}
\hline 30 & Kursi merk INTI & $15 / 07 / 2015$ & 3 & 1.000 .000 & $\begin{array}{l}67 \% \\
67 \% \\
67 \%\end{array}$ & $\begin{array}{l}2016 \\
2017 \\
2018\end{array}$ & $\begin{array}{c}666.667 \\
223.333 \\
73.700\end{array}$ & $\begin{array}{l}666.667 \\
890.000 \\
963.700\end{array}$ & $\begin{array}{c}333.333 \\
110.000 \\
36.300\end{array}$ \\
\hline 31 & Kursi merk INTI & $15 / 07 / 2015$ & 3 & 1.000 .000 & $\begin{array}{l}67 \% \\
67 \% \\
67 \%\end{array}$ & $\left|\begin{array}{l}2016 \\
2017 \\
2018\end{array}\right|$ & $\begin{array}{c}666.667 \\
223.333 \\
73.700\end{array}$ & $\begin{array}{l}666.667 \\
890.000 \\
963.700\end{array}$ & $\begin{array}{c}333.333 \\
110.000 \\
36.300\end{array}$ \\
\hline 32 & Alat Pemadam & 07/06/2014 & 3 & 9.350 .000 & $\begin{array}{l}67 \% \\
67 \% \\
67 \% \\
\end{array}$ & $\begin{array}{l}2015 \\
2016 \\
2017\end{array}$ & $\begin{array}{c}6.233 .333 \\
2.088 .167 \\
689.095\end{array}$ & $\begin{array}{l}6.233 .333 \\
8.321 .500 \\
9.010 .595\end{array}$ & $\begin{array}{c}3.116 .667 \\
1.028 .500 \\
339.405\end{array}$ \\
\hline 33 & Etalase & $15 / 10 / 2014$ & 3 & 5.868 .000 & $\begin{array}{l}67 \% \\
67 \% \\
67 \%\end{array}$ & $\left|\begin{array}{l}2015 \\
2016 \\
2017\end{array}\right|$ & $\begin{array}{c}3.912 .000 \\
1.310 .520 \\
432.472\end{array}$ & $\begin{array}{l}3.912 .000 \\
5.222 .520 \\
5.654 .992\end{array}$ & $\begin{array}{c}1.956 .000 \\
645.480 \\
213.008\end{array}$ \\
\hline
\end{tabular}

Sumber : Primkokas (dikelola penulis)

Berdasarkan tabel penyusutan aktiva tetap dapat dianalisa pada aset peralatan Primkokas,

a. Analisa penyusutan aktiva tetap menggunakan metode saldo menurun ganda, jika dilihat dari aset pertama, yakni pembelian Fujitsu LifeBook LH532V pada tanggal 5 Februari 2013 dengan harga perolehan Rp6.499.000 memiliki masa manfaat 5 tahun. Perhitungan penyusutan nya sebagai berikut. Dalam menggunakan metode saldo menurun ganda tarif penyusutan sebesar $40 \%$. Diperoleh dengan rumus $100 \%$ dibagi masa manfaat yakni 5 tahun dan dikali 2 (ganda).Penyusutan tahun pertama pada tahun 2014 diperoleh dari harga perolehan Rp 6.499 .000 dikali tarif $40 \%$ yaitu penyusutan sebesar Rp 2.599.600. Selanjutnya tahun kedua pada tahun 2015 penyusutan sebesar Rp 1.559.760 diperoleh dari tarif 40\% dikali nilai buku tahun sebelum Rp 3.899.400. Selanjutnya penyusutan tahun ketiga pada tahun 2016 sebesar Rp 935.856 diperoleh dari tarif $40 \%$ dikali nilai buku tahun sebelum Rp 2.339.640. selanjutnya penyusutan tahun keempat pada tahun 2017 sebesar Rp 561.514 diperoleh dari tarif 40\% dikali nilai buku tahun sebelum Rp 1.403.784. terakhir pada tahun kelima, tahun dimana akhir dari masa manfaat sebuah aset. Pada tahun 2018 penyusutan sebesar Rp 336.908 diperoleh dari tarif $40 \%$ dikali nilai buku tahun sebelum $\mathrm{Rp}$ 842.270.Pada perhitungan penyusutan aset peralatan menggunakan saldo menurun ganda diakhir tahun masa manfaat pada tahun 2018 memiliki total akumulasi sebesar Rp 5.993.638 dan nilai buku Rp 505.362, Jika dilihat dari nilai buku maka untuk aset Fujitsu LifeBook memiliki nilai sebesar Rp 505.362 di tahun 2018. Dengan total tersebut Primkokas bisa melakukan pelelangan atau menjual kembali dengan harga nilai buku tahun tersebut sesuai kebijakan perusahaan yang ada.

b. Perbandingan penyusutan aktiva tetap menggunakan metode garis lurus dan metode saldo menurun ganda. Pada metode garis lurus yang telah dipakai Primkokas menghasilkan beban penyusutan periodik yang sama sepanjang umur aktiva. Sedangkan metode saldo menurun ganda menghasilkan jumlah penyusutan yang lebih tinggi pada tahun - tahun awal pemakaian aset, yang kemudian terus menurun. Dalam 
hal ini metode saldo menurun ganda dapat dikatakan metode penyusutan dipercepat. Metode ini paling cocok dipakai jika penurunan produktivitas atau kemampuan menghasilkan pendapatan dari aset terjadi lebih tajam pada tahun - tahun awal pemakaian aset. Dengan alasan bahwa reparasi cenderung meningkat seiring dengan meningkatnya umur aset dan demikian berkurangnya jumlah penyusutan dalam tahun tahun akhir akan ditutupi oleh meningkatnya beban reparasi.Pada perhitungan penyusutan aset peralatan Fujitsu LifeBook LH532V- V4 dengan masa manfaat 5 tahun menggunakan saldo menurun ganda menghasilkan beban penyusutan $\mathrm{Rp} 336.908$ dengan nilai buku Rp505.362. sedangkan pada metode garis lurus menghasilkan beban penyusutan $\mathrm{Rp} 1.299 .800$ dengan nilai buku $\mathrm{Rp} 0$ atau tidak menghasilkan nilai buku pada akhir umur manfaat.

\section{KESIMPULAN.}

1. Dalam menggunakan metode saldo menurun ganda tarif penyusutan sebesar $40 \%$. Diperoleh dengan rumus $100 \%$ dibagi masa manfaat yakni 5 tahun dan dikali 2 (ganda). Penyusutan tahun pertama pada tahun 2014 diperoleh dari harga perolehan Rp 6.499.000 dikali tarif $40 \%$ yaitu penyusutan sebesar Rp 2.599.600. Selanjutnya tahun kedua pada tahun 2015 penyusutan sebesar Rp 1.559 .760 diperoleh dari tarif $40 \%$ dikali nilai buku tahun sebelum Rp 3.899.400. Selanjutnya penyusutan tahun ketiga pada tahun 2016 sebesar Rp 935.856 diperoleh daritarif $40 \%$ dikali nilai buku tahun sebelum $\mathrm{Rp}$ 2.339.640. selanjutnya penyusutan tahun keempat pada tahun 2017 sebesar Rp 561.514 diperoleh dari tarif $40 \%$ dikali nilai buku tahun sebelum Rp 1.403.784. Terakhir pada tahun kelima, tahun dimana akhir dari masa manfaat sebuah aset. Pada tahun 2018 penyusutan sebesar Rp 336.908 diperoleh dari tarif 40\% dikali nilai buku tahun sebelum Rp 842.270

2. Pada metode garis lurus yang telah dipakai Primkokas menghasilkan beban penyusutan periodik yang sama sepanjang umur aktiva. Sedangkan metode saldo menurun ganda menghasilkan jumlah penyusutan yang lebih tinggi pada tahun - tahun awal pemakaian aset, yang kemudian terus menurun. Dalam hal ini metode saldo menurun ganda dapat dikatakan metode penyusutan dipercepat. Metode ini paling cocok dipakai jika penurunan produktivitas atau kemampuan menghasilkan pendapatan dari aset terjadi lebih tajam pada tahun-tahun awal pemakaian aset. Dengan alasan bahwa reparasi cenderung meningkat seiring dengan meningkatnya umur aset dan demikian berkurangnya jumlah penyusutan dalam tahun - tahun akhir akan ditutupi oleh meningkatnya beban reparasi. Pada perhitungan penyusutan aset peralatan Fujitsu LifeBook LH532V-V4 dengan masa manfaat 5 tahun menggunakan saldo menurun ganda menghasilkan beban penyusutan Rp 336.908 dengan nilia buku Rp 505.362. sedangkan pada metode garis lurus menghasilkan beban penyusutan $\mathrm{Rp} 1.299 .800$ dengan nilai buku $\mathrm{Rp} 0$ atau tidak menghasilkan nilai buku pada akhir umur manfaat.

\section{SARAN}

Berdasarkan hasil dan pembahasan pada bab sebelumnya, maka ada beberapa saran yang ditujukan kepada perusahaan dan penelitian selanjutnya.

1. Analisa penyusutan aktiva tetap perusahaan sudah baik menghitung menggunakan metode garis lurus. Tetapi akan lebih baik lagi jika perusahaan menambahkan perhitungan nilai residu atau nilai sisa agar pada saat di lelang dapat diketahui bahwa aktiva tetap tersebut telah memberi manfaat lebih dari nilai perolehannya.

2. Yang perlu diingat bahwa manajemen dapat memilih satu atau lebih metode yang dianggap paling sesuai. Dan bila sudah menetapkan satu metode, harus ditetapkan secara 
konsisten, sepanjang masa penggunaan aktiva yang bersangkutan. Sehingga laporan keuangan dari periode ke periode dapat diperbandingkan.

\section{DAFTAR PUSTAKA}

[1] Aldila Septiana, M. (2019). ANALISIS LAPORAN KEUANGAN Konsep Dasar dan Deskripsi Laporan Keuangan. Duta Media Publishing.

[2] Dr. H. Salim, m. (2019). Penelitian Pendidikan Metode Pendekatan dan Jenis. Jakarta: Kencana.

[3] Lestari, P. A. (2020). Intermediate Accounting AKUNTANSI KEUANGAN MENENGAH. Jawa Tengah: Lakeisha.

[4] Manik, T. (2017). KOMPUTER AKUNTANSI: Praktik MYOB Accounting. UMRAH Press.

[5] Nurfadila, I. H. (2019). Akuntansi Dasar Buku Pintar Untuk Pemula. Yogyakarta: Deepublish.

[6] Rusmawati, Y. (2021). Total Quality Management. Bandung: Media Sains Indonesia.

[7] Sari, D. I. (2018). Analisis Depresiasi Aktiva Tetap Metode Garis Lurus dan Jumlah Angka Tahun PT. Adira Dinamika. Jurnal Moneter Vol. V No. 1.

[8] Sinarwati, N. K. (2021). Pengantar Akuntansi II. Depok: PT. RajaGrafindo Persada.

[9] Soetedjo, S. (2019). Pembahasan pokok-pokok pikiran teori akuntansi Vernon Kam.Surabaya: Airlangga University Press.

[10] Suhendar. (2021). PENGANTAR AKUNTANSI. Indramayu: Penerbit Adab.

[11] Tarigan, W. J. (2019). Analisis Penerapan Metode Penyusutan Aktiva Tetap dan Pengaruhnya Terhadap Laba Perusahaan pada PT. Jhonson \& Jhonson. Jurnal Ilmiah AccUsi - Vol 1, No 1. 